\title{
STRESS AND FATIGUE IN SOUND ENGINEERS: THE EFFECT OF BROADCASTING IN A LIFE SHOW AND SHIFT WORK
}

\author{
Katia K. Vangelova \\ National Center of Public Health Protection, Bulgaria
}

\begin{abstract}
SUMMARY
The aim was to study the time-of-day variations of cortisol, fatigue and sleep disturbances in sound engineers in relation to job task and shift work. The concentration of saliva cortisol and feeling of stress, sleepiness and fatigue were followed at three hour intervals in 21 sound engineers: 13 sound engineers, aged $45.1 \pm 7.3$ years, broadcasting in a life show during fast forward rotating shifts and 8 sound engineers, aged $47.1 \pm$ 9.8 years, making records in a studio during fast rotating day shifts. Cortisol concentration was assessed in saliva with radioimmunological kits. The participants reported for stress symptoms during the shifts and filled sleep diary. The data were analyzed by tests of between-subjects effects (SPSS). A trend for higher cortisol was found with the group broadcasting in a life show. The sound engineers broadcasting in a life show reported higher scores of stress, sleepiness and fatigue, but no significant differences concerning the sleep disturbances between the groups were found. In conclusion our data show moderate level of stress and fatigue with the studied sound engineers, higher with the subjects broadcasting in a life show. The quality of sleep showed no significant differences between the studied groups, an indication that the sound engineers were able to tolerate the fast forward rotating shifts.
\end{abstract}

Key words: field study, broadcasting in a life show, shift work, cortisol, fatigue, sleep disturbances

Address for correspondence: K. Vangelova, National Center of Public Health Protection, 15 Akad Ivan Geshov Boul., 1431 Sofia, Bulgaria. E-mail: katiavangelova@yahoo.com

\section{INTRODUCTION}

One of four subjects feels stressed at work, 10 to $12 \%$ of the people report that they are working under high occupational stress. The proportion of people working on shifts is increasing, too, and the combination of stressful job task with shift work is of special interest to the occupational medicine. The both factors are related to higher risk of sleep disturbances, fatigue and ill health (1-4), especially when the shift schedules involve night work. The rapid forward-rotating shift systems are considered to cause less problems and to promote faster recovery in relation to both sleep and social activities (5-7), is associated with better physical and psychological well being and lower level of fatigue (8). A variety of job task characteristics can influence stress level. The studied sound engineers consider the problems related to the sound equipment as the most stressful, followed by work under time pressure and ergonomic problems in the studios. Some of the sound engineers are engaged in a life show broadcasting, which could contribute to higher stress level, too.

Cortisol, a reliable indicator of stress, displays pronounced variation across the time of day and both shift work and stress may alter the secretion levels and circadian pattern. A long lasting increase of circulating cortisol levels or changes in the circadian rhythm of the hormone lead to allostatic load and are associated with increased risk of metabolic and cardiovascular diseases, depression, etc. (9-12).

The aim was to study the time-of-day variations of cortisol, fatigue and sleep disturbances in sound engineers in relation to their job task and shift work.

\section{STUDY POPULATION AND METHODS}

\section{Study Population and Design}

Our study involved 21 sound engineers from a radio department, working very fast forward rotating shifts. About $50 \%$ of the approached sound engineers agreed to participate in the study and were divided in two groups on the basis of job task, as follows: group I - 13 sound engineers broadcasting in a life show and working discontinuous forward rotating shifts (M A E R N $\mathrm{R}$ ) aged $45.1 \pm 7.3$ years with length of service $21.4 \pm 11.3$ years and group II - 8 sound engineers making records in a studio and working fast rotating morning, afternoon and evening shifts, aged $47.4 \pm 9.9$ years with length of service $24.5 \pm 7.1$ years. The start and the end of the shifts of the sound engineers broadcasting in a life show was as follows: morning shift - from 05:30 to 13:30, afternoon one from 11:30 to 19:30, the evening shift from 17:30 
to $24: 30$, night shift from 24:00 to $06: 00$. The start and end of working hours in studio recording engineers were the following: morning shift - from 07:00 to 15:00, afternoon one from 11:30 to 19:30, the evening shift from 14:00 to 22:00, so the start and the end of shift was the same for all the studied subjects only during the afternoon shift.

\section{Cortisol}

The concentration of saliva cortisol was followed three times a day starting at 12:00, then at 15:00 and at 18:00 hours. The participants were instructed to avoid food and liquids for 30 minutes before these time points. The cortisol samples were analyzed by radioimmunoassay using Spectria $\left({ }^{125} \mathrm{I}\right)$ radioimmunoassay kit (Orion Diagnostica, Finland). The within-assay coefficient of variation ranged from 0.8 to $5.2 \%$ and the between-assay coefficients never exceeded $8 \%$.

\section{Self-ratings}

At the above time points the participants made ratings in a diary concerning stress, sleepiness and fatigue. The stress scale included nine response categories (13), five included verbal anchors: 1 - very low stress (very calm and relaxed), 3 - low stress (calm and relaxed), 5 - neither low nor high stress, 7 - high stress (high tension and pressure), 9 - very high stress (very high tension and pressure). The participants also rated their sleepiness during the shifts using Karolinska Sleepiness Scale (KSS) (1 - very alert, 3 - alert, 5 - neither alert nor sleepy, 7 - sleepy, 9 - very sleepy, fighting sleep, effort to stay awake), validated against physiological and behavioral measures (14). During the shifts they also rated their feeling of fatigue using 9 point scale $(1$ - very fresh, 3 - fresh, 5 - neither fresh nor tired, 7 - tired, 9 - very tired).

At the end of the shift, the participants reported how their day had been in respect to different symptoms of stress. The questions were pointed towards gathering information whether one had felt tense, irritated, exhausted, under time pressure, or had difficulties in concentrating ( 1 - not at all, 5 - to a large extent) and whether they had enough rest during the day (1 - definitely enough, 5 - far from enough).

\section{Sleep Disturbances}

The participants filled in the Karolinska Sleep Diary (KSD) (15). It consists of questions concerning “sufficient sleep”, "early awaking”, "ease of falling asleep” and "stress or restlessness at bed”. Their answers were rated using 5 -point scale ( 1 - poor sleep, 5 - no problems with sleep). To measure the quality of sleep, a sleep quality index (SQI) was reflected in answering questions such as "restless sleep”, “ease of falling asleep”, “sleep quality” and "sleep throughout".

\section{Statistical Analyses}

The time-of-day variations of the studied indices were analyzed by tests of between-subjects effects (SPSS) and correlation analysis.

\section{RESULTS}

A trend for higher saliva cortisol $\left(\mathrm{F}_{(1,51)}=3.475, \mathrm{p}=0.068\right)$ was found in the group of sound engineers engaged in a life show broadcasting as compared to the group making records in a studio (Fig. 1). In both groups the cortisol values slightly decreased at the second time point following the diurnal pattern of the hormone, but increased at the end of the shift. No significant effect of the time-on-shift on cortisol secretion was found.

Significantly higher scores of stress $\left(\mathrm{F}_{(1,51)}=9.393\right.$, $\left.\mathrm{p}=0.004\right)$ were found in sound engineers engaged in a life show broadcasting (Fig. 2). Sleepiness did not differ significantly between the studied groups during the afternoon shift (Fig. 3), but increased significantly with shift advancing $\left(\mathrm{F}_{(1,51)}=4.240, \mathrm{p}=0.020\right)$. Sound engineers broadcasting in a life show showed higher level of

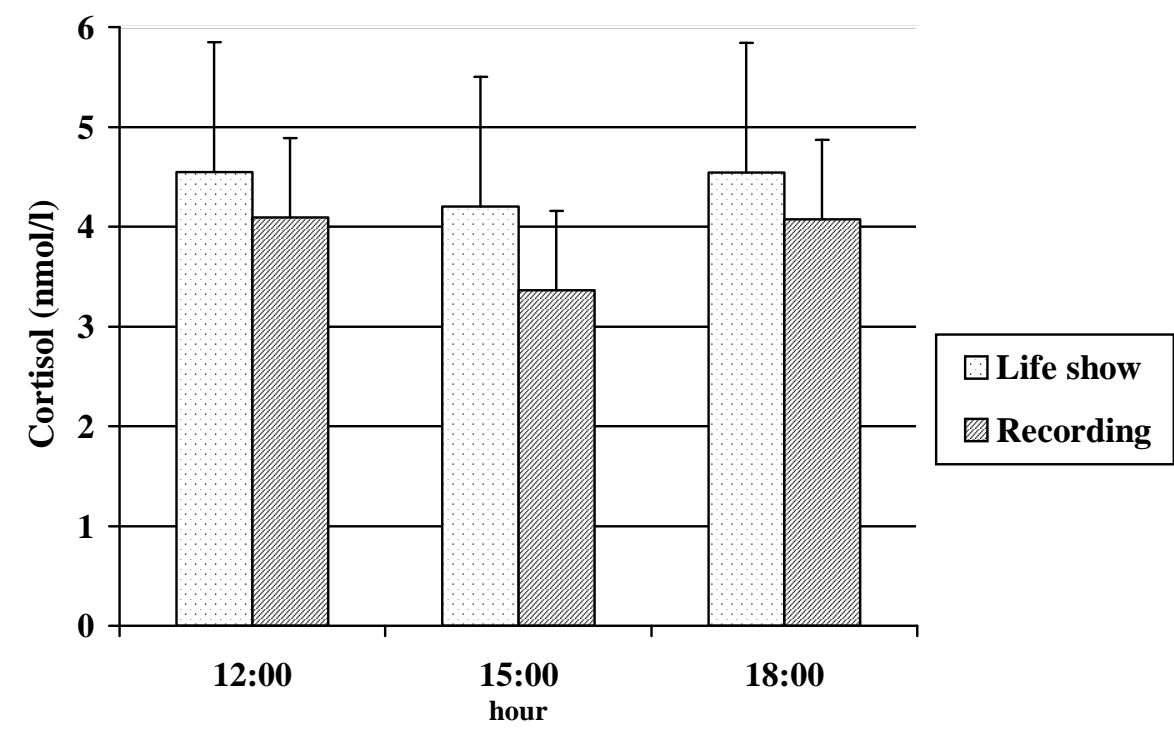

Fig. 1. Saliva cortisol in sound engineers broadcasting in a life show and making records in a studio during afternoon shift. 


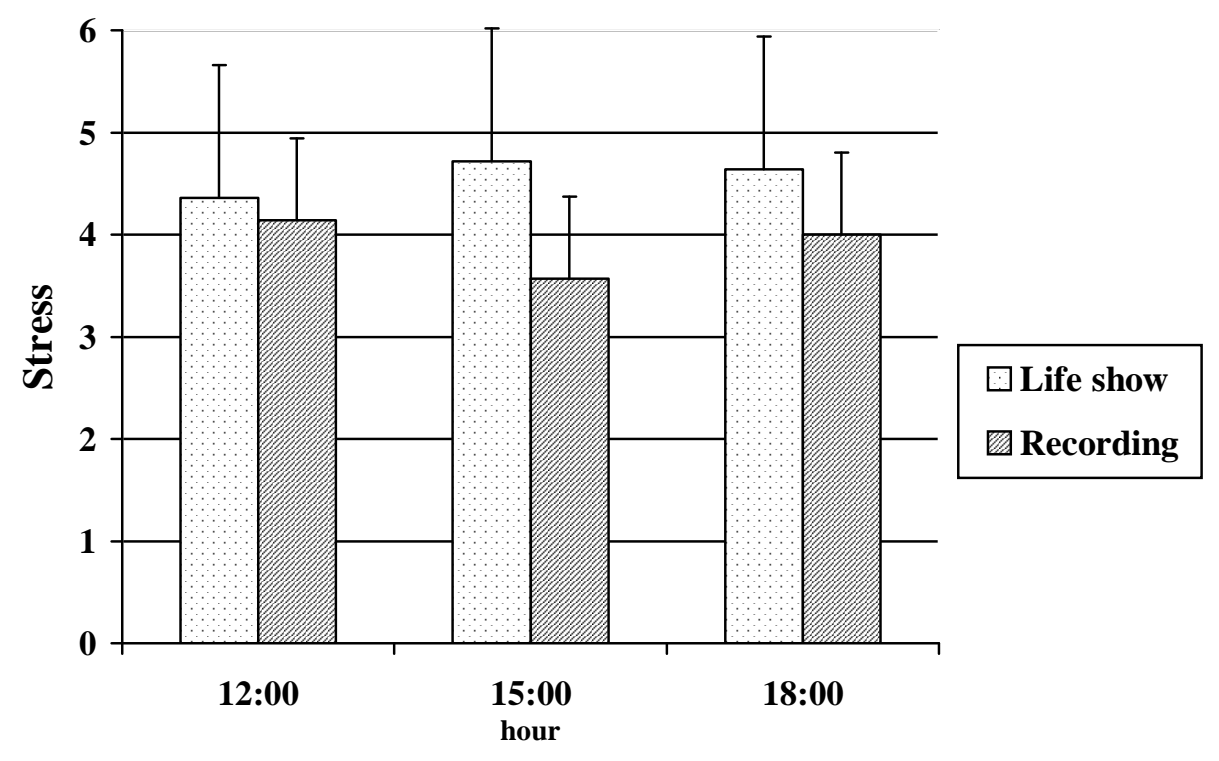

Fig. 2. Subjective feeling of stress in sound engineers broadcasting in a life show and making records in a studio during afternoon shift.

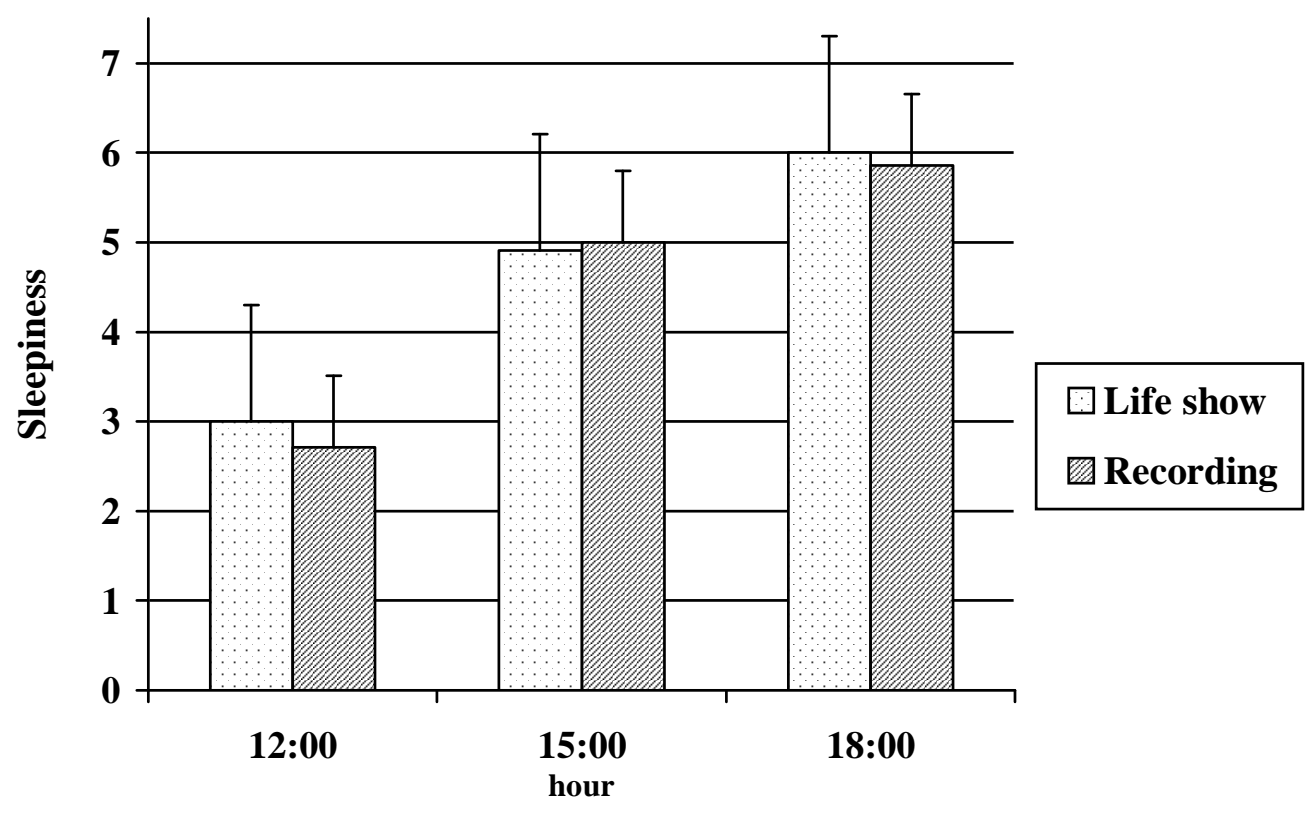

Fig. 3. Sleepiness in sound engineers broadcasting in a life show and making records in a studio during afternoon shift.

fatigue $\left(\mathrm{F}_{(1,51)}=6.300, \mathrm{p}=0.016\right)$. Fatigue increased with the timeon-shift in the frame of trend $\left(\mathrm{F}_{(2,51)}=2.374, \mathrm{p}=0.1\right)$ and was the highest at the end of the shift in both groups (Fig. 4).

Our data showed no significant differences between the two groups for the reported stress symptoms, except for the time pressure, reported to be significantly higher in sound engineers group making records in a studio $\left(\mathrm{F}_{(1,22)}=9.613, \mathrm{p}=0.007\right)$. The sound engineers felt moderately tense and irritated, but rather exhausted at the end of the shifts (Table 1). They found also that the work load was high and the rests during work not adequate.

The sleep duration was a bit of longer with the sound engineers making records in comparison to the ones broadcasting in a life show (Table 2), but no significant differences concerning sleep quality were found between the two groups. The quality of sleep, i.e. difficulties in falling asleep, fragmented sleep, and sleep quality index were rated as moderate by the two studied groups. 


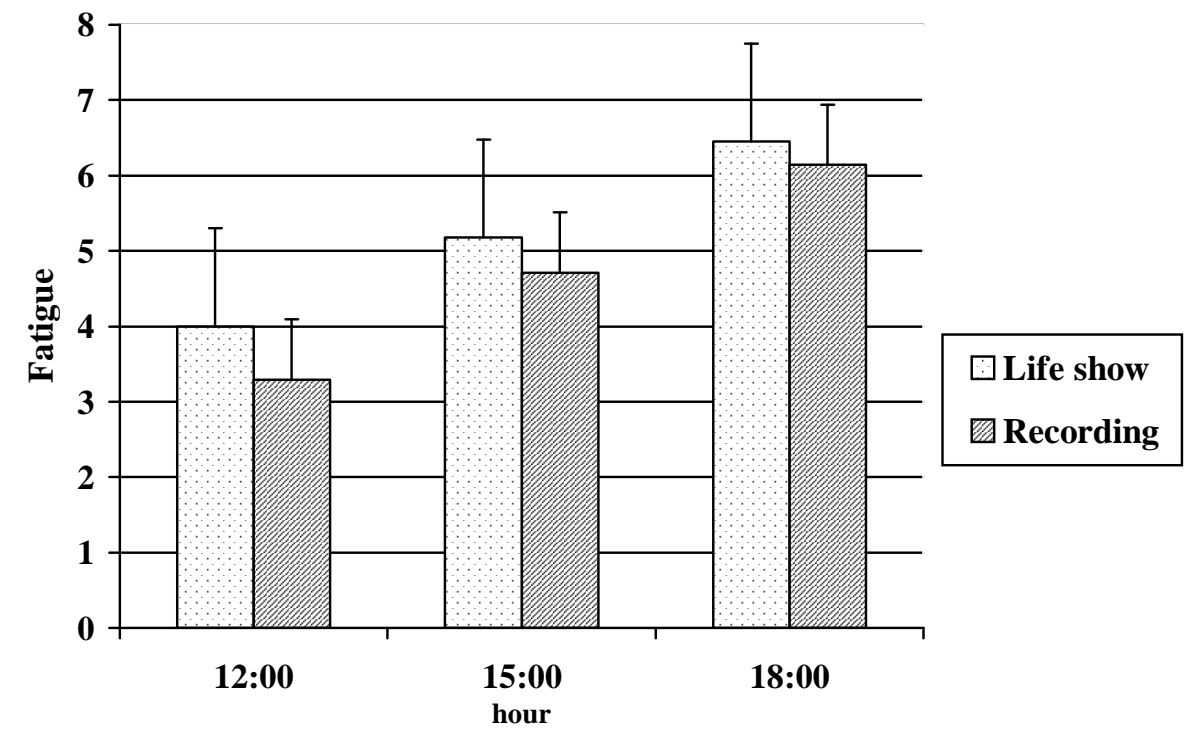

Fig. 4. Fatigue in sound engineers broadcasting in a life show and making records in a studio during afternoon shift.

Table 1. Stress symptoms at the end of the afternoon shift in sound engineers broadcasting in a life show and making records in a studio

\begin{tabular}{|l|c|c|}
\hline Indices (max score) & $\begin{array}{c}\text { Broadcasting } \\
\text { in a life show } \\
\text { (night shifts) }\end{array}$ & $\begin{array}{c}\text { Making records } \\
\text { in a studio } \\
\text { (no night shifts) }\end{array}$ \\
\hline Tense (max-5) & $3.63 \pm 0.92$ & $3.29 \pm 0.48$ \\
\hline Irritated (max-5) & $3.36 \pm 0.92$ & $3.43 \pm 0.53$ \\
\hline Exhausted (max-5) & $3.91 \pm 1.04$ & $3.43 \pm 0.53$ \\
\hline Time pressure (max-5) & $1.82 \pm \pm 0.87$ & $3.14 \pm 0.90$ \\
\hline $\begin{array}{l}\text { Problems with } \\
\text { concentration (max-5) }\end{array}$ & $3.18 \pm 0.98$ & $3.29 \pm 0.49$ \\
\hline High work load (max-5) & $3.72 \pm 0.78$ & $4.00 \pm 0.58$ \\
\hline Little time for rest (max-5) & $3.54 \pm 1.63$ & $3.86 \pm 1.07$ \\
\hline
\end{tabular}

\section{DISCUSSION}

Considering cortisol and self ratings our data showed moderate stress level with the both groups sound engineers. The cortisol values were slightly higher in the sound engineers broadcasting in a life show in comparison to the ones making records in a studio. Also the ratings of stress during the shift were higher in the former group. Unlikely cortisol and stress ratings during the
Table 2. Sleep duration and quality in sound engineers broadcasting in a life show and making records in a studio

\begin{tabular}{|l|c|c|}
\hline Indices & $\begin{array}{c}\text { Broadcasting } \\
\text { in a life show } \\
\text { (night shifts) }\end{array}$ & $\begin{array}{c}\text { Making records } \\
\text { in a studio } \\
\text { (no night shifts) }\end{array}$ \\
\hline Sleep (h) & $7.82 \pm 0.88$ & $8.35 \pm 1.00$ \\
\hline Sleep quality & $2.59 \pm 0.87$ & $2.80 \pm 0.87$ \\
\hline Sufficient sleep & $3.29 \pm 0.77$ & $2.90 \pm 0.57$ \\
\hline Fatigue at awakening & $3.00 \pm 0.87$ & $2.80 \pm 0.88$ \\
\hline Ease of falling asleep & $2.76 \pm 1.03$ & $2.70 \pm 0.82$ \\
\hline Sleep fragmentation & $2.94 \pm 0.83$ & $2.90 \pm 0.99$ \\
\hline Early awakening & $3.00 \pm 1.32$ & $3.70 \pm 1.06$ \\
\hline Sleep quality index & $2.71 \pm 0.62$ & $2.62 \pm 0.44$ \\
\hline
\end{tabular}

shift the engineers making records reported higher scores for time pressure, known to be associated with higher cortisol values in other occupational groups (16). The increase of cortisol at the end of the shift in both groups in comparison with the second time point is most probably associated with time pressure and stress, too, as earlier shown (17). Also, the both studied groups found that the work load was high and the rests during work not adequate, the sound engineers felt moderately tense and irritated, 
but rather exhausted at the end of the shifts, especially the ones broadcasting in a life show. The latter group showed higher level of sleepiness and fatigue during the shift.

One of the main problems with stress and shift work are the disorders of sleep $(1,2)$. Besides the sleep duration of the engineers making records in a studio was a bit of longer, no significant differences concerning sleep quality between the two groups were found. Taking into account that the sound engineers broadcasting in a life show worked discontinuous schedules with night shifts and showed higher stress at work, the lack of significant differences in sleep quality might be associated with comparatively low disruption of the circadian system with the fast forward rotating shifts, as was found in several studies earlier (18-20).

In conclusion our data show moderate level of stress and fatigue in the studied sound engineers, higher in the subjects broadcasting in a life show. The quality of sleep showed no significant differences between the studied groups, an indication that the sound engineers were able to tolerate the fast forward rotating shifts.

\section{REFERENCES}

1. Åkerstedt T. Shift work and disturbed sleep/wakefulness. Occup Med. 2003 Mar;53(2):89-94.

2. Costa G. Shift work and occupational medicine: an overview. Occup Med. 2003 Mar;53(2):83-8.

3. Bøggild H, Knutsson A. Shift work, risk factors and cardiovascular disease. Scand J Work Environ Health. 1999 Apr;25(2):85-99.

4. Knutsson A. Health disorders of shift workers. Occup Med. 2003 Mar;53(2):103-8.

5. Tucker P, Smith L, Macdonald I, Folkard S. Effects of direction of rotation in continuous and discontinuous 8 hour shift systems. Occup Environ Med. 2000 Oct;57(10):678-84.

6. Van Amelsvoort LG, Jansen NW, Swaen GM, van den Brandt PA, Kant I. Direction of shift rotation among three-shift workers in relation to psychological health and work-family conflict. Scand J Work Environ Health. 2004 Apr;30(2):149-56.

7. Härmä M, Hakola T, Kandolin I, Sallinen M, Virkkala J, Bonnefond A, et al. A controlled intervention study on the effects of a very rapidly forward rotating shift system on sleep-wakefulness and well-being among young and elderly shift workers. Int J Psychophysiol. 2006 Jan;59(1):70-9.
8. Barton J, Folkard S. Advancing versus delaying shift systems. Ergonomics. 1993 Jan-Mar;36(1-3):59-64.

9. Rosmond R, Dallman MF, Björntorp P. Stress-related cortisol secretion in men: relationships with abdominal obesity and endocrine, metabolic and hemodynamic abnormalities. J Clin Endocrinol Metab. 1998 Jun;83(6):1853-9.

10. Chrousos GP. The role of stress and the hypothalamic-pituitary-adrenal axis in the pathogenesis of the metabolic syndrome: neuro-endocrine and target tissue-related causes. Int J Obes Relat Metab Disord. 2000 Jun; 24 Suppl 2:S50-5

11. Kodat V, Sobota J, Kerza V, Biganovský M, Amortová R, Fisher J. Correlations of somatophysiological, biochemical, psychosocial and behavioral risk factors of cardiovascular diseases in a sample of employees of Prague enterprises and institutions. Cent Eur J Public Health. 2005 Dec;13(4):191-9.

12. Panagiotakos DB, Chrysohoou Ch, Pitsavos Ch, Antoniou S, Vavouranakis E, Stravopodis P. The association between occupational stress and the risk of developing acute coronary syndromes: the CARDIO2000 Study. Cent Eur J Public Health. 2003 Mar;11(1):25-30.

13. Dahlgren A, Kecklund G, Akerstedt T. Different levels of work-related stress and the effects on sleep, fatigue and cortisol. Scand J Work Environ Health. 2005;31(4):277-85.

14. Åkerstedt T, Gillberg M. Subjective and objective sleepiness in the active individual. Int J Neurosci. 1990 May;52(1-2):29-37.

15. Åkerstedt T, Hume K, Minors D, Waterhouse J. The subjective meaning of good sleep, an intraindividual approach using the Karolinska Sleep Diary. Percept Mot Skills. 1994 Aug;79(1 Pt 1):287-96.

16. Vangelova K. The effect of time pressure on the stress hormone reactivity in pharmacists. Ergonomia. Int J Ergon Hum Factors. 2004;26(4):2916.

17. Vangelova K. The excretion rates of stress hormones under mental work. Cent Eur J Public Health. 2005 Mar;13(1):47-50.

18. Cruz C, Detwiler C, Nesthus T, Boquet A. Clockwise and counterclockwise rotating shifts: effects on sleep duration, timing and quality. Aviat Space Environ Med. 2003 Jun;74(6Pt 1):597-605.

19. Boquet A, Cruz C, Nesthus T, Detwiler C, Knecht W, Holcomb K. Clockwise and counterclockwise rotating shifts: effects on temperature and neuroendocrine measures. Aviat Space Environ Med. 2004 Oct;75(10):898-904.

20. Sallinen M, Härmä M, Mutanen P, Ranta R, Virkkala J, Müller K. Sleepiness in various shift combinations of irregular shift systems. Ind Health. 2005 Jan;43(1):114-22. 